\title{
METODOLOGIA DE PROJETOS: PERSPECTIVAS DE APRENDIZAGEM ATIVA, SIGNIFICATIVA, CRÍTICA E TRANSFORMADORA
}

\author{
Josi Mariano Borille \\ Universidade Pontifícia Universidade Católica do Paraná - PUCPR (Brasil) \\ jmborille@yahoo.com.br .https://orcid.org/0000-00025849-0861 \\ Marilda Aparecida Behrens \\ Universidade Pontifícia Universidade Católica do Paraná - PUCPR (Brasil) \\ marildaab@gmail.com . https://orcid.org/0000-0002-3446-2321 \\ Mônica Aparecida Rodrigues Luppi \\ Pontifícia Universidade Católica do Paraná - PUCPR (Brasil) \\ monica@luppi.com.br.https://orcid.org/0000-0001-9957-4589
}

\begin{abstract}
Resumo. As Metodologias Ativas (MA) são caracterizadas pelo protagonismo do aluno no processo de ensino aprendizagem e pelo papel mediador e organizador do professor. Remontam da proposta de John Dewey, da década de trinta (século XX), porém vêm sendo retomadas com maior ênfase e abrangência nesta última década. A Metodologia de Projetos (MP) é uma MA composta por diferentes fases, permeadas de diversificadas estratégias que visam a produção de conhecimento e a aprendizagem ativa. Objetivou-se, neste texto, analisar e refletir sobre a MP, proposta por Behrens (2006), e propor uma (re)organização e (re) apresentação de suas fases com base na prática pedagógica docente das pesquisadoras, bem como discutir seu potencial de condução à aprendizagem ativa, significativa, crítica e transformadora, tendo como principal critério a pertinência e acolhimento das fases aos princípios da teoria da Aprendizagem Significativa (AS) (Ausubel, 1963) e a nova visão refletida na Aprendizagem Significativa Crítica (ASC) de Moreira (2010). A proposta foi denominada de Metodologia de Projetos em uma Perspectiva Ativa, Significativa, Crítica e Transformadora e a análise apontou pertinência e acolhimento a todos os princípios elencados da AS e da ASC. Ademais, sua utilização como MA e inovadora pode contribuir para a aprendizagem com significado e criticidade na produção do conhecimento.
\end{abstract}

Palavras-chave: Metodologia de Projetos, Aprendizagem Significativa, Aprendizagem Significativa Crítica, Metodologia Ativa e Inovadora, Produção de Conhecimento.

\section{PROJECT METHODOLOGY: PERSPECTIVES OF ACTIVE, MEANINGFUL, CRITICAL AND TRANSFORMATIVE LEARNING}

\begin{abstract}
Active methodologies (AM) are characterized by the student's protagonism in the teachinglearning process and by the teacher's mediating and organizing role. They date back to John Dewey's proposal, in the thirties of the twentieth century, but have been taken up with greater emphasis and scope in the past decade. The Project Methodology is an AM composed of different phases, permeated with diversified strategies that aim at the production of knowledge and active learning. This text aims to analyze and reflect on the Project Methodology, proposed by Behrens (2006) and to propose a (re) organization and (re) presentation of its phases based on the teaching pedagogical practice of the researchers, as well as discussing its potential leading to active, meaningful, critical and transformative learning, having as a main criterion the pertinence and acceptance of the phases to the principles of the Meaningful Learning (ML) theory (Ausubel, 1963) and the new vision reflected in the Critical Meaningful Learning (CML) of Moreira (2010). The proposal was called Project Methodology in an Active, Meaningful, Critical and Transformative Perspective and the analysis pointed out the pertinence and acceptance of all the principles listed in ML and CML and that its use as active and innovative methodologies can contribute to meaningful learning and criticality in the production of knowledge.
\end{abstract}


Keywords: Project Methodology, Meaningful Learning, Critical Meaningful Learning, Active and Innovative Methodology, Knowledge Production.

\title{
METODOLOGÍA DEL PROYECTO: PERSPECTIVAS DE APRENDIZAJE ACTIVO, SIGNIFICATIVO, CRÍTICO Y TRANSFORMADOR
}

\begin{abstract}
Resumen. Las metodologías activas (MA) se caracterizan por el papel del estudiante en el proceso de enseñanza-aprendizaje y por el papel de mediación y organización del maestro. Se remontan a la propuesta de John Dewey, en los años treinta del siglo XX, pero se han abordado con mayor énfasis y alcance en la última década. La Metodología del Proyecto es una maestría compuesta de diferentes fases, impregnada de estrategias diversificadas que apuntan a la producción de conocimiento y aprendizaje activo. El objetivo de este texto era analizar y reflexionar sobre la Metodología del Proyecto, propuesta por Behrens (2006) y proponer una (re) organización y (re) presentación de sus fases basadas en la práctica pedagógica de enseñanza de los investigadores, así como discutir su potencial que conduce a un aprendizaje activo, significativo, crítico y transformador, teniendo como criterio principal la pertinencia y aceptación de las fases a los principios de la teoría del Aprendizaje significativo (AS) (Ausubel, 1963) y la nueva visión reflejada en el Aprendizaje significativo crítico (ASC) de Moreira (2010). La propuesta se denominó Metodología del proyecto en una perspectiva activa, significativa, crítica y transformadora, y el análisis señaló la pertinencia y aceptación de todos los principios enumerados en AS y ASC y que su uso como MA e innovador puede contribuir a un aprendizaje significativo y criticidad en la producción de conocimiento.
\end{abstract}

Palabras clave: Metodología del proyecto, Aprendizaje significativo, Aprendizaje significativo crítico, Metodología activa e innovadora, Producción de conocimiento.

\section{Introdução}

As MA remontam da proposta de John Dewey, década de trinta, século XX, que influenciou educadores de várias partes do mundo. No Brasil, Dewey inspirou o movimento da Escola Nova, liderado por Anísio Teixeira, que influenciou diretamente o Manifesto dos Pioneiros, criado no Brasil em 1932, o qual propunha a integração da atividade prática e da democracia como importantes componentes da educação (Westbrook e Teixeira, 2010). Segundo Cunha (2001, p. 86), costuma ser frequente nas elaborações de Dewey "referência a noções como movimento, transformação e mudança, seja para caracterizar a sociedade, o indivíduo ou a escola..., a escola era vista como espaço privilegiado para a inserção do ímpeto transformador, uma escola transformada, evidentemente, uma educação nova.".

Nessa última década, as MA ressurgem no Brasil e acolhem diferentes propostas, como Metodologia de Projetos (MP), Aprendizagem Baseada em Problemas, Sala de Aula Invertida, entre outras. Nessas, uma das principais características é a centralidade do aluno no processo de ensino aprendizagem, o qual necessita participar ativamente, ser investigativo e corresponsável, juntamente com o professor, no processo de aprendizado. O professor tem o papel de organizador e mediador do processo.

A MP é considerada como MA, pois propõem um processo de aprendizagem que envolve a participação ativa do aluno e, segundo Behrens (2006) apresenta-se como estratégia metodológica inovadora para produção de conhecimento, visando aprendizagem ativa e significativa. 
A Aprendizagem Significativa (AS) de Ausubel (1963) é uma teoria cognitiva da aprendizagem, na qual os novos conhecimentos são produzidos a partir da interação cognitiva entre o novo conhecimento e o conhecimento prévio. Assim sendo, a partir do conhecimento prévio, novos conhecimentos podem ser ancorados à estrutura cognitiva, que somados a fatores, como, por exemplo, a disposição de aprender e outros princípios da AS, tal qual a diferenciação progressiva e reconciliação integradora, oportunizarão a aprendizagem com significado (Moreira, 2000).

Para além do significado, Moreira (2000, 2006, 2010) defende que a aprendizagem também precisa ser crítica e propõe uma nova visão da teoria, a Aprendizagem Significativa Crítica (ASC). Segundo o autor, para isso, é necessária a observação de alguns princípios norteadores (ou facilitadores), como a diversificação de materiais didáticos, abandono da narrativa pelo professor, interação social e questionamento, consciência semântica, entre outros.

Face ao exposto, este texto objetiva analisar e refletir sobre a Metodologia de Projetos de Behrens (2006), propondo uma (re)organização e (re)apresentação de suas fases, com base nas reflexões e na prática pedagógica das pesquisadoras, bem como discuti-las à luz da teoria da AS e de sua nova visão, a ASC, verificando a pertinência das fases aos princípios de ambas as teorias, assim como o potencial de condução à aprendizagem com significado e criticidade. Destacamos que na proposta original de MP de Behrens (2006), existe flexibilidade e abertura para revisitação da proposta e as reflexões sobre prática pedagógica das pesquisadoras ao longo dos anos, oportunizaram e motivaram este trabalho de revisitação e análise.

\section{Metodologia da pesquisa}

Esta pesquisa, de natureza qualitativa e exploratória (Gil, 2002), teve como referência a MP de Behrens (2006 e 2014) que, por sua vez, toma como referência a teoria de Dewey aliando-a aos fundamentos da teoria da AS e aos de sua mais nova visão, a ASC de Moreira (2000, 2006, 2010). Partindo desse referencial, buscou-se a (re)organização e (re)apresentação da proposta de MP, acrescentando, suprimindo e/ou reorganizando fases.

Para o processo de (re)elaboração da proposta, foram consideradas as reflexões e ações da prática docente das pesquisadoras ao longo dos anos, em especial, na formação de professores no contexto universitário, e as estratégias metodológicas exitosas de ensino e aprendizagem, que têm, particularmente, contribuído para a formação de alunos investigadores na produção do conhecimento, bem como de alunos dotados de espírito crítico, consciente e participativo na vida em sociedade. Assim, tais ações e reflexões sobre a prática pedagógica das pesquisadoras, foram incorporadas a proposta, complementando as fases da MP já descrita por Behrens $(2006,2014)$ e exemplificando ações que podem ser realizadas em cada fase, sempre priorizando o protagonismo do aluno e mediador do professor, porém sem detalhamentos do contexto e dos sujeitos que participaram do processo.

Após elaboração da nova proposta, traçamos uma análise à luz das teorias da AS e ASC e de seus princípios, observando a acolhida das fases aos princípios norteadores de ambas as teorias. 


\section{Metodologia de Projetos}

A Metodologia de Projetos data do início do século XX, quando J. Dewey (1916) e W. H. Kilpatrick (1918), referenciados por Boutinet (2002, p.181), apresentam oposição à pedagogia tradicional propondo "uma pedagogia progressista, também chamada de pedagogia aberta, na qual o aluno se tornava ator de sua formação por meio de aprendizagens concretas e significativas para ele". A intenção de Dewey e Kilpatrick, ao propor uma pedagogia de projetos, envolvia a transformação da visão de aluno como sujeito de sua própria aprendizagem (Boutinet, 2002).

Ao longo da história da educação, a MP recebeu denominações diferentes, assim como enfrentou muitas críticas e preconceitos no meio educacional, pois, muitas vezes, carregou a impressão de ensino improvisado (Boutinet, 2002).

Nas obras de Behrens (2006, 2014), a autora afirma que o trabalho com projetos vem se ressignificando como MA em um sentido muito mais amplo do que de trabalhos temáticos isolados, bem como ganhando importante espaço na prática pedagógica docente. Para além do significado de apenas "projetar", tal metodologia subsidia os processos de ensino e aprendizagem definindo etapas e estratégias metodológicas interconectadas na produção do conhecimento. As propostas mais atuais dessa metodologia oportunizam a participação ativa do aluno no processo de aprendizagem, a mediação e organização da situação de ensino por parte do professor e o pluralismo de recursos metodológicos, características essas das MA e inovadoras (Behrens, 2006, 2014).

A denominação de Metodologia de Projetos, segundo Behrens (2000, 2006), acolhe uma metodologia comprometida com os propósitos pedagógicos de natureza inovadora e capaz de oportunizar a aprendizagem em um processo mais amplo, a partir de uma visão inter/transdisciplinar. Desse modo, representa um processo metodológico de aprendizagem que envolve níveis de integração, interconexão, inter-relacionamento e agregação de informações, conteúdos, conhecimentos e a religação de saberes (Morin, 2009) na busca de uma abordagem complexa.

Neste contexto, a MP vem ao encontro do que propõe Morin (2009, p. 13) no que se refere à ideia de que a sociedade se encontra ante o desafio de considerar a educação sob uma concepção cada vez mais ampla, que supere a visão reducionista, "profunda e grave entre saberes separados, fragmentados, compartimentados entre disciplinas, e, por outro lado, realidades ou problemas cada vez mais polidisciplinares, transversais, multidimensionais, transnacionais, globais e planetários”. A fragmentação dificulta a visão de contexto e, muitas vezes, impede o entendimento do todo. Ademais, na concepção de Morin (2009, p.15), o desenvolvimento da ciência de forma disciplinar, "não só trouxeram as vantagens da divisão do trabalho, mas também os inconvenientes da supervalorização, do confinamento e do despedaçamento do saber. Não só produziram o conhecimento, mas também a ignorância e a cegueira".

Na MP, conforme Behrens (2006), em primeiro lugar, o professor apresenta para os alunos um problema, tomando como referência os conteúdos que devem ser trabalhados naquela fase de escolarização. Assim, a partir de uma situação problematizada de aprendizagem, os próprios estudantes começam a participar do processo de criação, pois buscam respostas às suas dúvidas. Mas não lhes interessa apenas localizá-las, e sim entender o significado delas, pois pretendem, como resultado, a construção de conhecimentos significativos. Aprendem, assim, a partir do problema, buscam informações, elegem o que é significativo para responder ao questionamento, elaboram e produzem conhecimento. 
Na MP, Behrens (2000) propõe algumas fases que podem auxiliar na produção do conhecimento (Figura 1). As fases inter-relacionadas que subsidiam o processo de aprendizagem numa metodologia de projetos com visão complexa, crítica e transformadora, podem ser compostas como dadas na figura que segue.

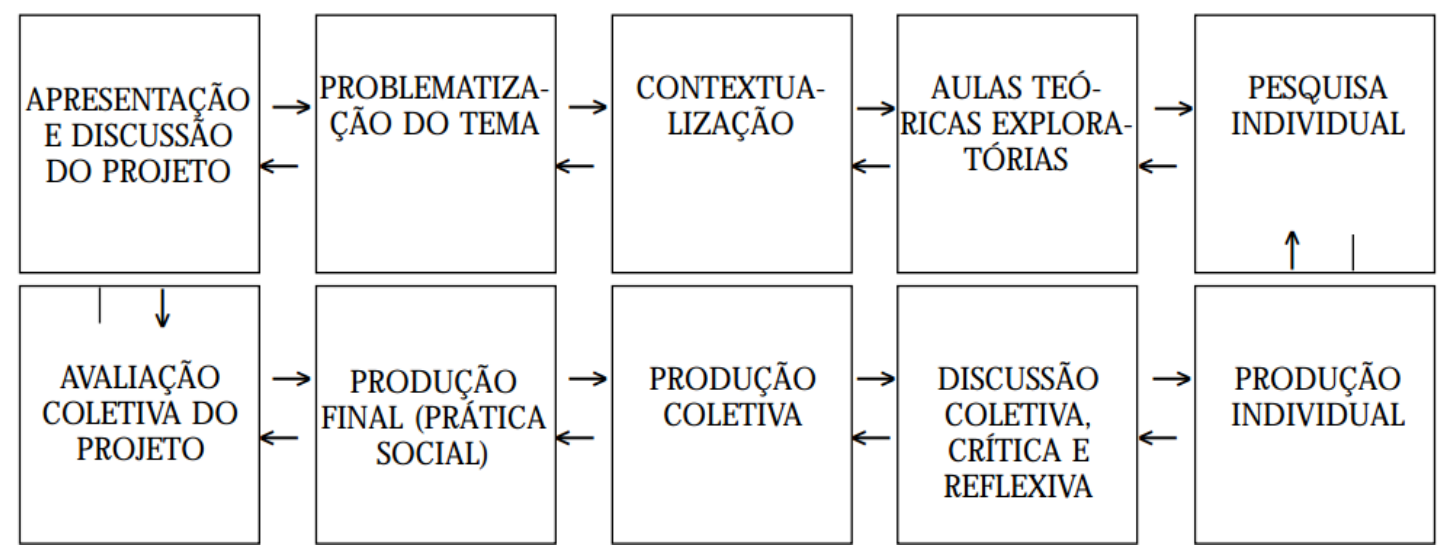

Figura 1. Fases da Metodologia de Projetos propostas por Behrens (2000).

Para a autora, trata-se de uma metodologia flexível, que vai se construindo ao longo do processo em cada aprendizagem, renovando-se a cada problema colocado que gere outra aprendizagem significativa. Portanto, sua natureza não é "fechada" e "acabada", podendo, assim, ser dinâmica e ressignificada, pois a autora alerta que essas fases são sugestões e, de acordo com a criatividade do professor, podem ser aumentadas, reordenadas e readequadas, conforme às necessidades de aprendizagens do grupo de alunos. Tal flexibilidade da proposta de Behrens (2000) foi um dos fatores motivadores para realizar essa análise e reflexão e reelaborar uma nova proposta reorganizada e analisá-la, tomando como base a aliança com os princípios da AS e da ASC.

\section{A AS e seus princípios}

As obras, 'A psicologia da aprendizagem verbal significativa' (1963) e 'Psicologia da Educação: uma visão cognitiva' (1968), publicadas por David Ausubel, apresentam as ideias que fundamentam a denominada Teoria da Aprendizagem Significativa. Mais tarde, com os trabalhos de Joseph D. Novak e Helen Hanesian (1980), tais obras são revisitadas e publicadas novamente, reafirmando a teoria que sustentou a obra 'A aquisição e retenção de conhecimento: uma visão cognitiva' (2000).

$\mathrm{Na}$ teoria da AS, a aprendizagem com significado ocorre pela interação cognitiva entre o novo conhecimento e o conhecimento prévio. Nesse processo, que é não-literal e não-arbitrário, o novo conhecimento, adquire significados para o aprendiz e o conhecimento prévio fica mais rico, mais diferenciado, mais elaborado, em termos de significados, e adquire mais relevância (Moreira e Masini, 1982, 2006, Moreira,1999, 2000, 2006, Masini e Moreira, 2008, Valadares e Moreira, 2009). Para a maioria dos autores anteriormente citados, e já desde Ausubel (1963), o conhecimento prévio é, isoladamente, a variável que mais influencia a aprendizagem. Ou seja, só podemos aprender a partir daquilo que já se conhece.

$\mathrm{Na}$ AS, o aprendiz não é um receptor passivo. Ele deve fazer uso dos significados que já internalizou, de maneira substantiva e não arbitrária, para poder captar os significados dos materiais educativos. Nesse processo, ao mesmo tempo que está progressivamente diferenciando sua estrutura cognitiva, está, também, fazendo a reconciliação integradora, de modo a identificar semelhanças e diferenças para 
reorganizar seu conhecimento, ou seja, o aprendiz constrói e produz seu conhecimento (Moreira, 2010).

Oliveira, Frota e Martins (2013) destacam que é necessário que o professor busque novas metodologias para que o aluno aprenda de maneira significativa. Nesta teoria, alguns princípios programáticos são facilitadores dessa aprendizagem, como a diferenciação progressiva, a reconciliação integradora, a organização sequencial e a consolidação (Ausubel et al. 1980, 1983, Moreira e Buchweitz 1987, 1993, Moreira, 2006). Além disso, algumas estratégias são facilitadoras, como os organizadores prévios, os mapas conceituais e os diagramas em V (Novak e Gowin, 1984, 1988, 1996) (Figura 2).

\section{A ASC e seus princípios}

A ASC é uma nova visão da AS de Ausubel, proposta por Moreira (2010). Sobre esta teoria, o autor inspirou-se nas ideias de Neil Postman e Charles Weingartner (1969), em seu livro "Ensino e atividade subversiva", e, também, em algumas reflexões de Postman em livros mais recentes, como o Technopoly (1993) (Tecnopólio) e The End of Education (1996) (O fim da educação)".

Moreira (2011) defende que a aprendizagem para além de significativa precisa também ser subversiva ou crítica. Ele argumenta que, nestes tempos de mudanças rápidas e drásticas que vivemos atualmente, a ASC é uma estratégia fundamental para sobreviver na sociedade contemporânea.

A ASC é aquela perspectiva que permite ao sujeito fazer parte de sua cultura e, ao mesmo tempo, estar fora dela, não sendo, assim, subjugado por ela, por seus ritos, mitos e ideologias. Trata-se de uma perspectiva antropológica em relação às atividades de seu grupo social, que permite ao indivíduo participar de tais atividades, mas, ao mesmo tempo, reconhecer quando a realidade está se afastando tanto que não está mais sendo captada pelo grupo (Moreira, 2011).

Assim, tendo como referência as propostas de Postman e Weingartner (1969), Moreira (2000, 2006 e 2010) propõe essa nova visão e aponta onze princípios necessários para que, de fato, a aprendizagem seja significativa e crítica, registrados na Figura 2. 


\section{Organizadores prévios}

Materiais introdutórios apresentados antes do material de aprendizagem, que servirão de ponte entre os conhecimentos prévios e os que o estudante deveria saber para que esse material fosse potencialmente significativo ("ancoradouros provisórios").

\section{Diferenciação Progressiva}

As ideias mais gerais, inclusivas e relevantes devem ser apresentadas no início da instrução e, progressivamente, diferenciadas em termos de detalhes e especificidade (...) para, em seguida, ser trabalhado por meio de exemplos, situações, exercícios.

\section{Reconciliação integradora}

Consiste em explorar, explicitamente, relações entre conceitos e proposições, chamando a atenção para diferenças e semelhanças e buscando reconciliar inconsistências reais e aparentes.

\section{Organização sequencial}

Consiste em sequenciar os tópicos, ou unidades de estudo, de maneira tão coerente quanto possível (observados os princípios de diferenciação progressiva e reconciliação integrativa).

\section{Consolidação}

Insistir no domínio do que está sendo estudado, antes que novos materiais sejam introduzidos, assegura-se contínua prontidão na matéria de ensino e alta probabilidade de êxito na aprendizagem sequencialmente organizada.

\section{Mapas conceituais}

Diagrama que indica relação entre conceitos.

\section{Diagramas em V}

Instrumentos heurísticos para a análise da estrutura do processo de produção de conhecimento.

\section{Pré-disposição para aprender}

É necessário que o aprendiz manifeste intenção em querer aprender significativamente.

Figura 2. Princípios programáticos e estratégias facilitadoras da AS

Nota: Adaptado de Ausubel (1963) e Moreira (2006). 


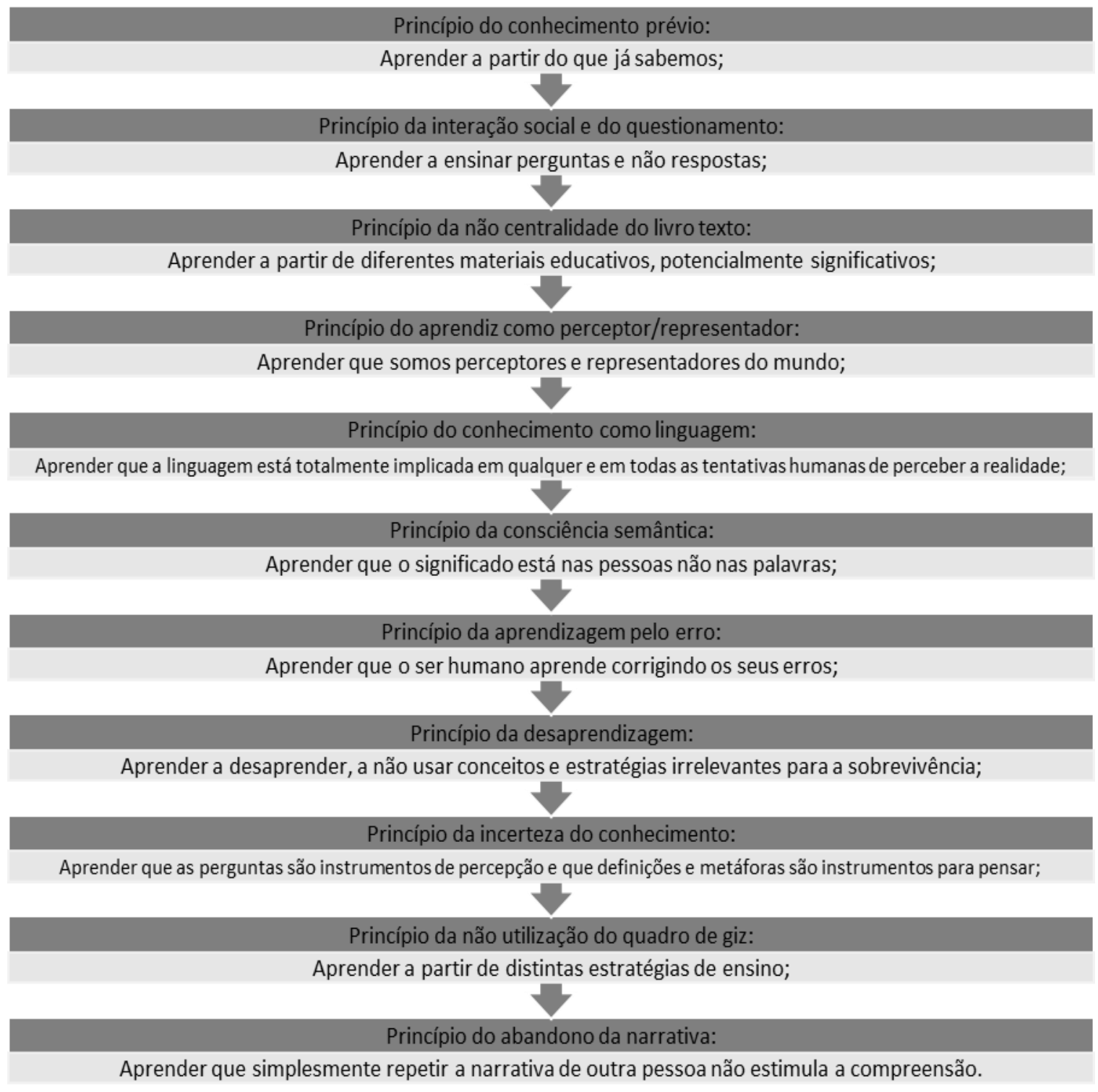

Figura 3. Princípios facilitadores da ASC

Nota: Adaptado com base em Moreira (2000, 2006, 2011).

\section{A Metodologia de Projetos em uma Perspectiva Ativa, Significativa, Crítica e Transformadora}

- A proposta

A Figura 4 demonstra a Metodologia de Projetos, proposta por Behrens (2006), e a nova proposta, denominada como Metodologia de Projetos em uma Perspectiva Ativa, Significativa, Crítica e transformadora, sendo que mais adiante procurou-se estabelecer as relações e reflexões tomando por base a teoria da AS e da ASC. 


\section{Fases da Metodologia de Projetos}

\begin{tabular}{|ll}
\hline \multicolumn{1}{c}{$\begin{array}{c}\text { Metodologia de Projetos } \\
\text { Behrens (2000, 2006 e 2014) }\end{array}$} & $\begin{array}{c}\text { Metodologia de Projetos em uma Perspectiva Ativa, } \\
\text { Significativa, Crítica e Transformadora }\end{array}$ \\
\hline 1. Apresentação e Discussão do Projeto & 1.Escolha do tema \\
\hline 2. Escolha do Tema & 2. Avaliação Diagnóstica \\
\hline 3. Problematização & 3. Planejamento \\
\hline 4. Contextualização & 4. Apresentação e discussão do projeto \\
\hline 5. Exposição teórica & 5. Contextualização e Problematização \\
\hline 6. Pesquisa individual & 6. Exposição teórica \\
\hline 7. Produção individual & 7. Pesquisa e produção individual \\
8. Discussão crítica & 8. Roda de conversa/Discussão crítica/ Exposição \\
\hline 9. Produção coletiva & 9. Produção coletiva e colaborativa \\
\hline 10. Produção final & 10. Apresentação/compartilhamento \\
11. Avaliação da aprendizagem & produções coletivas \\
\hline 12. Avaliação coletiva & 11.Produção final com ação/aplicação \\
\hline & 12. Avaliação diagnóstica final individual \\
\hline
\end{tabular}

Figura 4. Fases da Metodologia de Projetos de Behrens (2000, 2006, 2014) e da Metodologia de Projetos em uma Perspectiva Ativa, Significativa, Crítica e transformadora.

$\mathrm{Na}$ sequência, são apresentadas as definições das fases da proposta, com explicações e caracterizações das mesmas, assim como alguns exemplos de atividades que podem ser utilizadas em cada fase.

\section{Escolha do tema}

Nesta fase, o professor, juntamente com os alunos, escolhe o tema de trabalho, oriundo de componentes curriculares ou mediante assuntos que estejam sendo amplamente debatidos no meio escolar, na sociedade e/ou veiculado na mídia.

\section{Avaliação diagnóstica}

Esta fase tem por objetivo de identificar os conhecimentos que os alunos já possuem sobre o tema escolhido e subsidiar a próxima fase desta proposta. Ao reconhecer os conceitos ou nível de conhecimento que os alunos já possuem sobre a temática, o professor pode melhor planejar seu trabalho. Sugerem-se aqui os mapas mentais ou conceituais como importantes ferramentas, como também outro método de escolha de professor que permita tal diagnose.

\section{Planejamento}

Partindo da análise da fase anterior o professor realiza seu planejamento, definindo problema, objetivos, conteúdos, metodologia de trabalho e atividades a serem desenvolvidas, bem como mecanismos de avaliação. Elabora-se, nesta fase, o texto base do trabalho por projetos. Entende-se por texto base a elaboração do documento que conste os itens e as descrições da proposta de trabalho. Cabe ressaltar que, muitas vezes, esse planejamento é provisório, pois, perfeitamente, podem ser acrescidos objetivos e atividades ao trabalho no decorrer de seu desenvolvimento. 


\section{Apresentação e discussão do projeto}

Nesta fase, o professor faz a apresentação e discussão do projeto junto a turma, submetendo-o à apreciação, discussão e possíveis alterações, tais como acréscimos e supressões. Nesta fase, também, podem ser estabelecidas funções ou papéis dos alunos e professor quanto à metodologia de trabalho.

\section{Contextualização e Problematização}

A contextualização do tema escolhido pode ocorrer nos diferentes cenários que se fizerem oportunos (municipal, estadual, federal ou pessoal, escolar, familiar, social, entre outros) a fim de, identificar o problema a ser solucionado durante o desenvolvimento das atividades. É interessante que aluno e professor tenham ciência do porquê tal tema está sendo trabalhado e quais aprendizagens serão necessárias para subsidiar a compreensão deste e outros temas futuros.

\section{Exposição Teórica}

A fase de Exposição Teórica é imprescindível no ensino por MP. O professor expõe as ideias iniciais, lança informações, indica leituras e recursos a serem utilizados pelos alunos para início da produção do conhecimento que subsidiará a próxima fase, a pesquisa individual. As aulas expositivas e dialogadas podem ser a estratégia utilizada para esta fase, pois elas podem e devem fazer parte da prática pedagógica docente, mesmo no contexto das MA. Nesta fase, ou na próxima, algumas MA, como a sala de aula invertida, podem auxiliar professor e alunos a iniciar a construção do conhecimento.

\section{Pesquisa e produção individual}

Nesta fase, os alunos são convidados a ampliar seus conhecimentos por meio da pesquisa e produção individual, que pode ser generalista ou específica sobre algum assunto dentro da temática do projeto. O professor pode elaborar um roteiro coletivo dos itens que devem compor a pesquisa, assim como orientar a elaboração da produção textual que poderá ser um resumo com as informações encontradas e/ou, ainda, a opinião ou posicionamento pessoal sobre o assunto.

Tais produções podem ser arquivadas por meio de portfólios impressos ou online para que alunos e professores possam acompanhar a evolução na construção e produção do conhecimento. Nesta fase, assim como em outras, o professor assume o importante papel de organizador da situação de aprendizagem.

\section{Roda de conversa/Exposição e Discussão crítica}

$\mathrm{Na}$ sequência, os alunos são convidados a expor os resultados de sua pesquisa e produção. As rodas de conversa e os debates orientados são indicadas para esta fase, em que o professor terá importante papel de motivar os alunos a exporem suas produções e opiniões, promovendo a discussão crítica e reflexiva sobre os dados encontrados. É importante garantir a participação de todos, podendo-se reunir grupos de alunos que compartilhem da mesma opinião ou adotando-se outro critério de exposição. Técnicas de ensino e aprendizagem como os Grupos de Verbalização e Observação (GVGO) podem ser utilizadas e associadas ao uso de mapas de discussão, instrumentos que demonstram graficamente a participação dos alunos no debate e podem servir ao professor como instrumentos de avaliação e mediação dos debates e exposições.

\section{Produção coletiva e colaborativa}

Posteriormente, os alunos devem ser reunidos em grupos para início da próxima fase, a de produção coletiva. É importante que, para essa produção, sejam definidos previamente os critérios de formação dos grupos, a ênfase das produções, seja listando os 
pontos convergentes, divergentes, ou fazendo proposição de itens mínimos que comporão o texto. Para além da produção, é necessário que o aluno aprenda a trabalhar em equipe de forma colaborativa, respeitando as decisões tomadas em consenso e opiniões dos demais colegas e sabendo, também, defender a sua opinião e posição, quando necessário. Sugere-se para esta fase a elaboração de documentos online de caráter compartilhado, nos quais as informações possam ser acrescidas de forma colaborativa. Uma indicação é a utilização do Google que possibilita a abertura e compartilhamento de documentos online para trabalhos colaborativos. Podem ser usados, também, murais eletrônicos, o site Padlet é um exemplo. Técnicas como o Painel integrado também possibilitam produções colaborativas, e podem ser integradas aos portfólios.

\section{Apresentação ou compartilhamento das produções coletivas}

A apresentação das produções coletivas pode ser feita por meio de roda de conversa, seminários, exposições orais ou ilustrativas (cartazes, murais físicos ou online, entre outros). Tais produções podem, ainda, ser armazenadas e compartilhadas por meio de ferramentas digitais e online.

\section{Produção final com ação/aplicação}

Nesta fase, já de adiantado conhecimento sobre o tema, os alunos são convidados a pensar uma forma de ação ou aplicação do tema. Nesta fase, é oportunizado ao aluno a aplicação do conhecimento científico como prática social e reflexiva. Sugere-se a elaboração de documentos, síntese das aprendizagens construídas, ou informativos, tais como cartas, folders, podcasts, vídeos, palestras de conscientização nas instituições de ensino ou comunidade, a fim de contribuir amplamente sobre a divulgação da temática.

\section{Avaliação diagnóstica final individual}

Nesta fase, o professor elabora uma avaliação diagnóstica final e individual sobre o desenvolvimento do projeto e as aprendizagens construídas durante o trabalho. Sugerese que, nesta fase, seja feita a (re)aplicação da produção de mapas mentais ou conceituais ou, ainda, uma produção textual informativa e de opinião. Independentemente da atividade escolhida para esta fase, ela deve também compor o portfólio do aluno.

\section{Avaliação da Aprendizagem}

A avaliação da aprendizagem poderá ocorrer pela análise dos portfólios físicos ou online, organizados ao longo do projeto. Neste processo, professor e aluno podem analisar e refletir sobre o processo de ensino e aprendizagem durante o desenvolvimento do projeto, podem analisar seu progresso, suas aprendizagens construídas no processo e produção do conhecimento e realizar sua avaliação e auto avaliação, respectivamente. É importante que, ao avaliar, o professor tenha critérios previamente estabelecidos, sendo tais critérios também de conhecimento dos alunos. A capacidade de produção, síntese, posicionamento, argumentação, exposição de ideias, contribuição no grupo, contribuições sociais são alguns dos importantes critérios que podem ser estabelecidos previamente e levados em consideração na avaliação. A fase descrita anteriormente pode ser um dos itens que comporão a avaliação da aprendizagem, mas não único, pois a avaliação poderá ocorrer em diferentes dimensões, sendo elas a auto avaliação e avaliação dos colegas (de si e dos demais alunos), do professor, da metodologia utilizada, da própria avaliação, entre outros aspectos. 


\section{Avaliação coletiva/ Avaliação dos resultados}

Nesta fase, os alunos são convidados a avaliar o projeto em si e seu desenvolvimento. Eles podem apontar as contribuições oportunizadas por meio das diferentes atividades realizadas, assim como refletir sobre sua participação e contribuição. Pode-se avaliar, ainda, possíveis impactos dos resultados do projeto na turma ou na prática social realizada por meio da ação/aplicação (fase 12). Tal fase pode ser realizada de forma escrita ou oral, usando novamente a roda de conversa como estratégia.

Figura 5. Fases recriadas para a Metodologia de Projetos numa Perspectiva Significativa, Ativa, Crítica e Transformadora

\section{Metodologia de Projetos e Princípios da Aprendizagem Significativa e da Aprendizagem Significativa Crítica: reflexões e análises}

A análise e discussão sobre a pertinência e acolhimento das fases da proposta à teoria da AS e ASC estão presentes na Tabela 1. De forma geral, verifica-se que todas as fases da proposta atenderam a pelo menos um dos princípios de ambas as teorias. A seguir, explicamos mais detalhes destas relações e de que modo compreendemos a contribuição dessa proposta para a promoção da ASC.

As fases Escolha do tema e Avaliação Diagnóstica, assim como a de Planejamento, atendem de forma bastante pertinente aos princípios: Organizadores Prévios e Princípio do Conhecimento Prévio. O conhecimento dos conceitos e conhecimentos já existentes por parte do aluno é, de fato, muito importante para a condução da aprendizagem significativa crítica, pois, ao reconhecer o que os alunos sabem sobre determinado assunto, torna-se possível um melhor planejamento do trabalho pedagógico e possibilidades mais concretas de aprendizagem, visto que são nesses conceitos, já presentes na estrutura cognitiva e conhecidos (subsunçores), que os demais serão ancorados, oportunizando uma AS (Ausubel, 1963, Moreira, 2010).

A importância do conhecimento prévio é defendida por autores, como Postman e Weingartner (1969, p. 62) e Freire. Os primeiros afirmam que aprendemos somente em relação ao que já sabemos, e Freire, segundo Almeida (2009, p. 82), afirma que "os professores preparam suas aulas levando em conta o que os alunos sabem, que eles não são mais elementos vazios, tornam-se um ponto de partida de toda a aprendizagem".

Porém, pode ocorrer de os subsunçores não existirem na estrutura cognitiva dos alunos, sendo, então, necessário oferecer aos alunos estratégias que possibilitem a ancoragem para os novos conceitos. Ou, os subsunçores podem estar obliterados ou deturpados, impedindo os aprendizes de captar os significados do novo conhecimento, tornando-se necessária a desaprendizagem (Princípio da desaprendizagem).

Para ambos os casos citados, a principal estratégia, advogada por Ausubel (1963, p. 148) para deliberadamente manipular a estrutura cognitiva, é a utilização dos organizadores prévios, que "são materiais introdutórios apresentados antes do material de aprendizagem em si, em um nível mais alto de abstração, generalidade e inclusividade. Sua principal função é a de servir de ponte entre o que o aprendiz já sabe e o que ele deve saber a fim de que o novo material possa ser aprendido de maneira significativa. Seriam uma espécie de "ancoradouro provisório".

Assim, cabe ao professor auxiliar o aluno a reconhecer o conhecimento prévio necessário para ancoragem do novo conhecimento ou suas deturpações, processo esse realizado nas fases de diagnose inicial, planejamento, exposição e discussão do projeto. 
As diferentes estratégias metodológicas, em seus diferentes formatos, presentes nessa proposta, refletem o seu pluralismo metodológico, permitindo-nos inferir que os princípios da não centralidade do livro texto, da não utilização do quadro de giz, do abandono da narrativa, da interação social e do questionamento e do princípio do conhecimento como linguagem estão contemplados. Entende-se, que os princípios, anteriormente citados, especialmente os três primeiros, não precisam, necessariamente, ser abolidos, mas que sejam utilizadas em menor escala, oportunizando maior protagonismo do aluno.

Segundo Moreira (2000), o uso de distintas estratégias que impliquem participação ativa do estudante e, de fato, promovam um ensino centralizado no aluno é fundamental para facilitar a ASC, corroborando os princípios das MA, centralidade do aluno no processo e professor como mediador.

Para Moreira (2000), um ensino baseado em respostas transmitidas do professor para o aluno nas aulas e, do aluno para o professor na avaliação, não é crítico e tende a gerar aprendizagem não crítica e mecânica. Por outro lado, um ensino centrado na interação entre professor e aluno, enfatizando o intercâmbio de perguntas, tende a ser crítico e suscitar a ASC. Dessa forma, a MP nas fases Apresentação e discussão do projeto e Contextualização e problematização e Roda de conversa/Exposição e Discussão crítica, entre outras, oportuniza ao aluno e professor não só o processo de interação social e questionamento, como também a capacidade de exposição, reflexão e elaboração de questionamentos.

Nesse mesmo entendimento, a proposta contempla o princípio do conhecimento como linguagem, uma vez que em todas as suas fases necessitam e utilizam-se da linguagem. "Não existe nada entre seres humanos que não seja instigado, negociado, esclarecido, ou mistificado pela linguagem, incluindo nossas tentativas de adquirir conhecimento. A linguagem é a mediadora de toda a percepção humana". (Postman, 1996, P. 123).

Na proposta, também pode-se inferir a contemplação do Princípio do aprendiz como perceptor e representador da realidade. A ASC implica a percepção crítica e só pode ser facilitada se o aluno for, de fato, tratado como um perceptor do mundo e, portanto, do que lhe for ensinado e, a partir daí, um representador do mundo e do que lhe é ensinado. Da mesma forma, professor é também um perceptor, o que ensina é fruto de suas percepções, assim, a comunicação só será possível na medida em que dois perceptores, professor e aluno, buscarem perceber de maneira semelhante os materiais educativos propostos. Isso corrobora a importância da interação pessoal e do questionamento na facilitação da ASC, contemplado desde a fase Diagnóstica inicial até à fase Avaliação Coletiva/Avaliação dos Resultados.

Para Moreira (2000), e, de acordo com o Princípio da consciência semântica, é preciso aprender que o significado está nas pessoas e não nas palavras. Para Gowin (1981), um episódio de ensino se consuma quando aluno e professor compartilham significados sobre os materiais educativos. Assim, ao serem oportunizados momentos de produção individual e coletivas, que, posteriormente, são compartilhados em espaços coletivos, professor e aluno e aluno e aluno compartilham suas visões e significados, discutem e refletem sobre suas percepções e representações sobre elas.

O princípio da incerteza do conhecimento prediz que se deve aprender que as perguntas são instrumentos de percepção e que definições e metáforas são instrumentos para pensar. Este princípio chama atenção porque a visão de mundo é construída, primordialmente, com as definições do que se cria, com as perguntas que se formula e 
com as metáforas que se utiliza. Assim, é preciso compreender que o conhecimento é fruto de nossa construção e não se pode tê-lo como verdade inquestionável e acabada, sendo necessário sempre o questionamento e a dúvida, em detrimento das certezas (Moreira, 2000). Assim, é importante oportunizar ao aluno momentos de reflexão e questionamento sobre o próprio conhecimento e produção. Com maior ênfase, contemplase este princípio nas fases de Roda de Conversa/Discussão Crítica e Reflexiva e Apresentação e Compartilhamento das produções (individual e coletiva).

$\mathrm{Na}$ MP, na qual o professor tem um papel mais de organizador da situação de aprendizagem e o aluno tem papel mais ativo, é natural que o erro se apresente no processo de ensino aprendizagem - Princípio da aprendizagem pelo erro. Cabe ao professor, o papel de auxiliar o aluno a encarar o erro como processo natural e como mecanismo de aprendizagem. Ao aluno, cabe o papel de em cada etapa da proposta a possibilidade de (re) aprender quando necessário. 


\section{Tabela 1}

Relações da Metodologia de Projetos em uma Perspectiva Ativa, Significativa, Crítica Transformadora com as teorias da AS e ASC

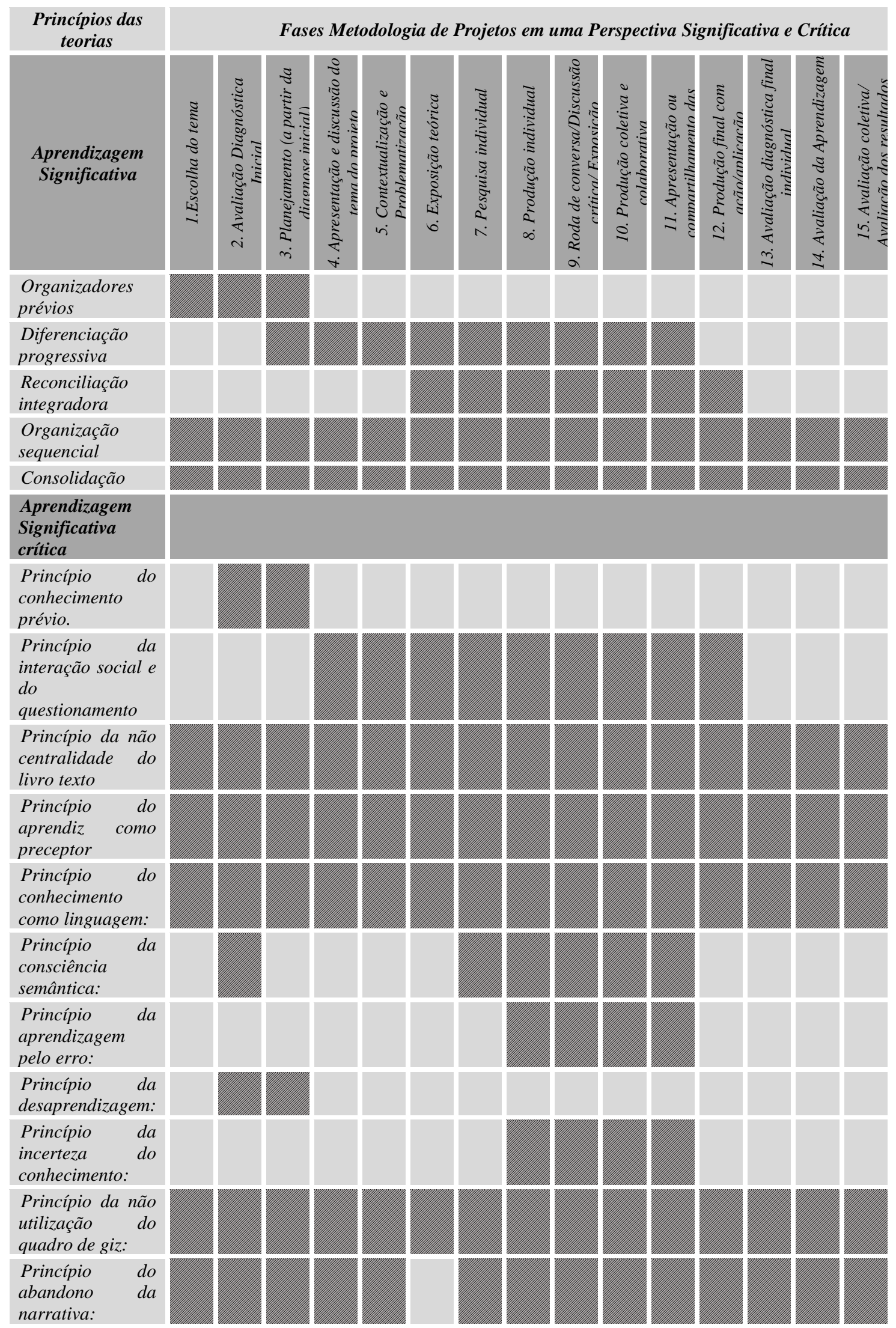


Por fim, pode-se, também, inferir relação dessa proposta ao Princípio da organização sequencial, que consiste em sequenciar os tópicos, ou unidades de estudo, de maneira tão coerente quanto possível (observados os princípios de diferenciação progressiva e reconciliação integrativa) e ao Princípio da consolidação, que prevê, primeiramente, o domínio do que está sendo estudado, antes de introduzir novos materiais conforme Moreira (2000) A estruturação da proposta apresentada foi pensada visando oportunizar ao aluno uma melhor forma de construção e apropriação do conhecimento, respeitando seus conhecimentos prévios a partir de um processo investigativo e ativo para sua consolidação. Ao oferecer-lhe momentos de produção individual, coletiva e oportunidades de compartilhar e discutir suas produções, entende-se que se oportuniza momentos de exposição, de acordo com suas pesquisas e entendimento, a oportunidade de (re) visão ao ouvir as produções de outros colegas e o (com)senso, ao produzir coletivamente. Também destaca-se que toda proposta parte de ideias inclusivas e generalistas para, então, ao final, oportunizar os conhecimentos específicos e reconciliálos integrativamente. A organização em fases subsequentes demonstra claramente isto.

Acrescenta-se, ainda, que a MP auxilia na necessidade de superar a visão reducionista na educação, pois proporciona ao aluno uma visão mais integrada dos conteúdos escolares, assim como, por conseguinte, da natureza, da sociedade e do ambiente. Destaca-se, aqui, o alerta de Morin (2001, p. 15) para visão disciplinar em currículos lineares, pois "[...] nos ensinam a isolar os objetos (do seu meio ambiente), a separar as disciplinas (em vez de reconhecer suas correlações), a dissociar os problemas, em vez de reunir e integrar"; e acrescenta: "Obrigam-nos a reduzir o complexo ao simples, isto é, a separar o que está ligado; a decompor, e não a recompor; a eliminar tudo o que causa desordens ou contradições em nosso entendimento".

É fato, também, que as metodologias tradicionais, caracterizadas pela transmissão e reprodução do conhecimento, não dão conta de ensinar e aprender de forma significativa e crítica, assim a MP, na perspectiva ativa, crítica e transformadora, enquanto MA, que oportuniza o trabalho ativo e investigativo do aluno na produção do conhecimento, pode ser uma importante estratégia importante na prática docente de professores que buscam uma prática pedagógica inovadora.

\section{Considerações finais}

Consideramos que a Metodologia de Projetos em uma Perspectiva Ativa, Significativa, Crítica e Transformadora, proposta e analisada a luz das teorias AS e ASC (objetivo deste trabalho), demonstrou pertinência e acolhimento de suas fases para com os princípios de ambas a teorias, sendo possível assim inferirmos que tal proposta apresenta alto potencial de aprendizagem com significado e criticidade, visto que muitas relações puderam ser estabelecidas nas fases recriadas e criadas.

Com base em Moreira (2000), que muito amparou esta discussão, cabe finalizar este texto fazendo referência novamente ao princípio do aprendiz como perceptor/representador da realidade, segundo o qual todos somos perceptores e interpretadores da realidade. Nesse sentido, destaca-se que que as relações estabelecidas nesta proposta podem, a qualquer momento, ser revisitadas, (re) discutidas e até (re) significadas. E ainda, parafraseando Moreira (2000), cabe ressaltar que, em tempos de mudanças rápidas e drásticas, a aprendizagem para além de significativa, deve ser, também, crítica sendo uma estratégia necessária para viver na sociedade atual. Neste contexto, emerge a importância da inserção de MA, como a MP, em diferentes áreas do 
conhecimento para, assim, oportunizar a produção do conhecimento com autonomia, criticidade e significado.

\section{Referências}

Almeida, F. J. (2009). Paulo Freire. Folha Explica, v. 81. São Paulo: Publifolha.

Ausubel, D. (1963). The psychology of meaningful verbal learning. New York: Grune and Stratton.

Ausubel, D., Novak, J. D. e Hanesian, H. (1980). Psicologia educacional. Rio de Janeiro: Interamericana. Tradução para o português do original Educational psychology: a cognitive view.

Ausubel, D., Novak, J. D. e Hanesian, H. (1983). Psicología educativa: un punto de vista cognoscitivo. México: Editorial Trillas. Tradução para o espanhol do original Educational psychology: a cognitive view.

Behrens, M. A. (2000). Projetos de aprendizagem colaborativa num paradigma emergente. In: Moran, J. M. Masetto, M. T e Behrens, M. A. Novas tecnologias e mediação pedagógica (p.67-132). Campinas: Papirus.

Behrens, M. A. (2005). O Paradigma Emergente e a Prática Pedagógica. Petrópolis: Vozes.

Behrens, M. A. (2006). O paradigma da complexidade. Metodologia de projetos, contratos didáticos e portfólios. Petrópolis:Vozes.

Behrens, M. A. (2006). Metodologia de projetos num paradigma emergente. In: M.A. Behrens, Paradigma da complexidade (p.33-74). Petrópolis: Vozes.

Behrens, M. A. (2014). Metodologia de projetos: Aprender e Ensinar para a produção do conhecimento em uma visão complexa. In: P.L. Torres (org.) Complexidade: Redes e Conexões na Produção do Conhecimento(p.95-116). Curitiba: SENAR.

Boutinet, J. (2002). Antropologia do Projeto. Porto Alegre: ArtMed.

Cunha, M. V. (2001). John Dewey e o pensamento educacional brasileiro: a centralidade da noção de movimento, Revista Brasileira de Educação, Maio/Jun/Jul/Ago, $N^{o}$ $17,86-99$.

Gil, A. C. (2002). Como elaborar projetos de pesquisa. São Paulo: Ed. Atlas.

Gowin, D. B. (1981). Educating. Ithaca: Cornell University Press.

Moreira, M. A. (1999). Aprendizagem significativa. Brasília: Editora da UnB.

Moreira, M. A. (2000). Aprendizaje significativo: teoría y práctica. Madrid: VISOR.

Moreira, M. A. (2006). A teoria da aprendizagem significativa e sua implementação em sala de aula. Brasília: Editora da UnB.

Moreira, M. A. (2006). Mapas conceituais e diagramas V. Porto Alegre: Ed. do Autor.

Moreira M. A. (2010). Mapas conceituais e aprendizagem significativa. São Paulo: Centauro.

Moreira, M. A. (2011). Aprendizagem significativa: a teoria e textos complementares, São Paulo: LF Editorial.

Moreira, M. A. e Buchweitz, B. (1987). Mapas conceituais: instrumentos didáticos de avaliação e de análise de currículo. São Paulo: Moraes.

Moreira, M. A. e Buchweitz, B. (1993). Novas estratégias de ensino e aprendizagem: os mapas conceituais e o Vê epistemológico. Lisboa: Plátano Edições Técnicas.

Moreira, M.A. e Masini, E.A.S. (1982). Aprendizagem significativa: a teoria de aprendizagem de David Ausubel. São Paulo: Editora Moraes.

Moreira, M. A. e Masini, E. A.S. (2006). Aprendizagem significativa: a teoria de aprendizagem de David Ausubel. $2^{\mathrm{a}}$ ed. São Paulo: Centauro Editora.

Morin, E. (2001). A religação dos saberes: o desafio do século XXI. Tradução e notas Flávia Nascimento. Rio de Janeiro: Bertrand. 
Morin, E. (2009). A cabeça bem feita. Repensar a reforma. Reformar o pensamento. 16. ed. Rio de Janeiro: Bertrand,

Novak, J. D. (2000). Aprender, criar e utilizar o conhecimento. Mapas conceptuais como ferramentas de facilitação nas escolas e empresas. Lisboa: Plátano Universitária. 252p. Tradução para o português do original Learning, creating, and using knowledge. Concept maps as facilitating tools in schools and corporations.

Novak, J. D. e Gowin, D. B. (1984). Learning how to learn. Cambridge: Cambridge University Press.

Novak, J D. e Gowin, D. B. (1988). Aprendiendo a aprender. Barcelona: Martínez Roca. Tradução para o espanhol do original Learning how to learn.

Novak, J. D. e Gowin, D. B. (1996). Aprendendo a aprender. Lisboa: Plátano Edições Técnicas. Tradução para o português do original Learning how to learn.

Oliveira, M. M., Frota, P. R. de O. e Martins, M. C. (2013). Mapas conceituais como estratégias para o ensino de educação ambiental. Revista Electrónica de Investigación y Docencia (REID). 61-72. Recuperado de http://www.revistareid.net/monografico/n9/REIDM9art4.pdf.

Postman, N. (1996). The end of education: redefining the value of school. New York: Vintage Books/Random House.

Postman, N. (1993). Technopoly: the surrender of culture to technology. New York: Vintage Books/Random House.

Postman, N e Weingartner, C. (1969). Teaching as a subversive activity. New York: Dell Publishing Co.

Valadares, J. A. e Moreira, M. A. (2009). A teoria da aprendizagem significativa: sua fundamentação e implementação. Coimbra: Edições Almedina.

Westbrook, R.B. e Teixeira, A. (2010). John Dewey. Tradução de Romão, J.E., Rodrigues, V. L. (org.) Recife: Fundação Joaquim Nabuco, Editora Massangana.

Data de recepção: 06/06/2020

Data de revisão: $13 / 07 / 2020$

Data do aceite: 20/07/2020 